\title{
Correction of a Skeletal Class III Malocclusion with Chin Cap Therapy- A Case Report
}

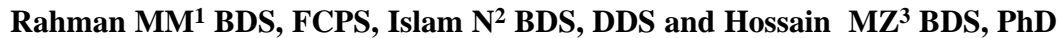

\begin{abstract}
Case with skeletal and dental class III malocclusion is presented. The patient was a seven year-old girl with growth potential, having anterior and posterior cross bite, premature loss of mandibular deciduous molar teeth bilaterly. The patients soft tissue profile was concave.The general treatment included chin cap, palatal expansion and comprehensive edge wise orthodontic therapy.
\end{abstract}

Key Words : Skeletal and dental class III, Cross bite, Chin cap, palatal expansion (Ban J Orthod \& Dentofac Orthop 2010; Vol-1, No. 1, 13-15)

\section{CASE HISTORY}

The patient, a healthy girl of seven years came to the Dhaka Dental college Hospital, Department of orthodontics and Dento facial orthopedic with the complain of lower part of face is becoming larger day by day. The chief concern expressed by the family was her facial appearance. Family history was positive as her cousin had similar abnormal growth pattern.

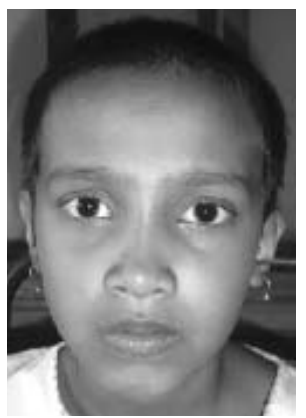

Fig. 1: Frontal view

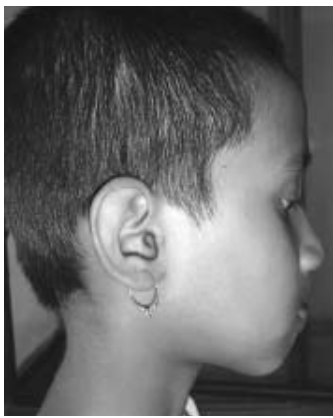

Fig. 2: Profile view

\section{Extra Oral Examination}

- Profile-concave.

- Facial asymmetry present.

- Mandible-prognathic.

- Face anteriorly-divergent.

\section{CLINICAL EXAMINATION}

Intra Oral : The molar relationship was Angles class-III (Fig.1). The upper deciduous incisors were slightly crowded and deciduous molar are grossly carious. There was premature loss of mandibular deciduous molars on both sides. But the patient did not have any TMJ symptoms. There was a slight lower midline shifted to the right.
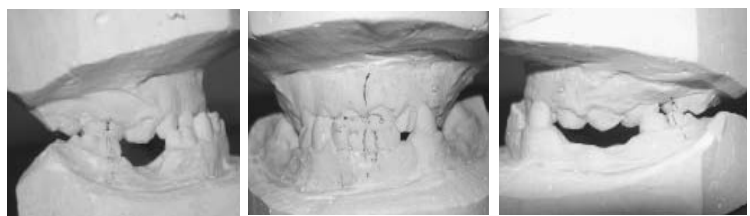

Fig. 3 : Right view, frontal view, left view

- The model analysis revealed stage of mixed dentition. The molar relation is class- III on both sides. Both anterior and posterior cross bite present. The reverse over jet is $4.5 \mathrm{~mm}$ and over bite is $4 \mathrm{~mm}$. Lower deciduous molars are absent, upper deciduous molar are grossly carious.

\section{RADIOPATHY EXAMINATION}

OPG analysis: the panoromic radiograph revealed that the patient was a stage of mixed dentition. All the first permanent molar were erupted, lower central incisors were erupting and crowded in position. All the permanent tooth germs were present and normal in position (Fig 4).

Cephalometric Analysis: The Ceplalometric radiograph and its tracing (Fig 5) illustrated an SNA angle of 71 degree, SNB angle of 77 degree, ANB angle of -6 degree and inter incisor angle of 142 degree. The SNA angle suggests a retrusive maxilla.

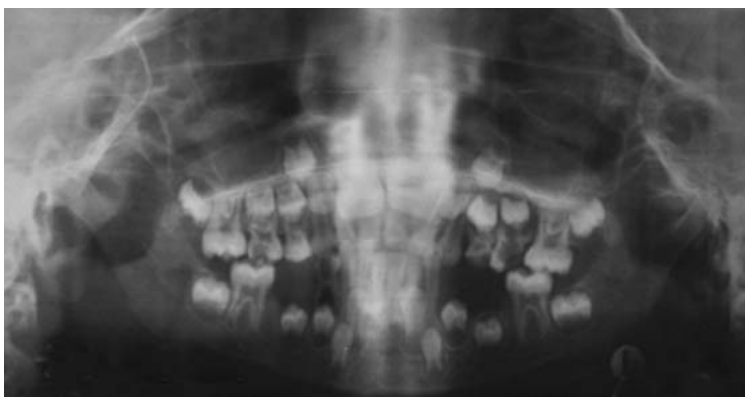

Fig. 4 : OPG

${ }^{1}$ Lecturer, Department of Orthodontics \& Dentofacial Orthopedics, Dhaka Dental College. ${ }^{2}$ Asstt. Professor \& Head, Dept. of Science of Dental Materials, Dhaka Dental College. ${ }^{3}$ Professor \& Head, Department of Orthodontics \& Dentofacial Orthopedics, Dhaka Dental College. 


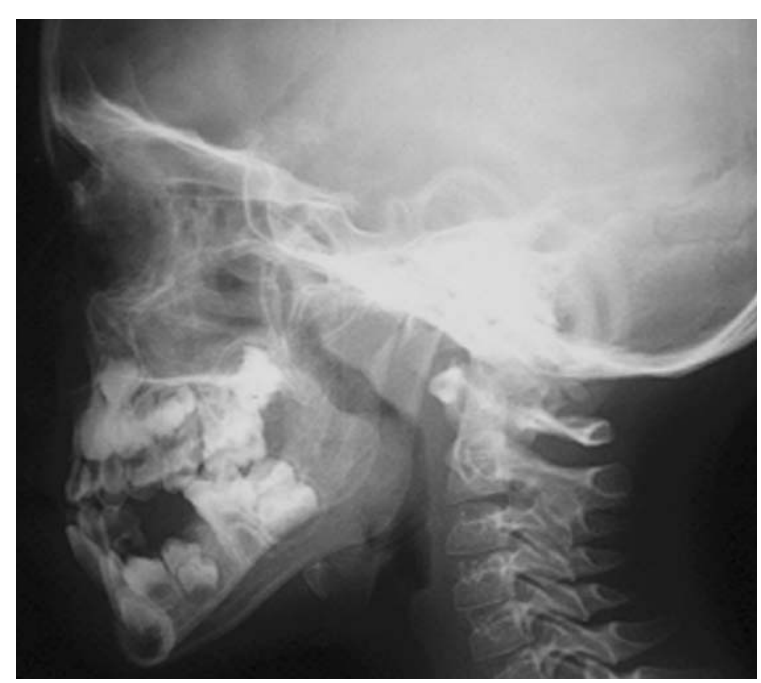

Fig. 5: Lateral cephalogram

\section{DIAGNOSIS}

The patient was diagnosed as a skeletal and dental class-III malocclusion. The cast analysis revealed class-III molar relationship on both sides and presence of anterior and posterior cross bite. The anterior cross bite produced a reverse over bite of $4 \mathrm{~mm}$ and reverse over jet of $4.5 \mathrm{~mm}$. The mid line of lower arch had shifted approximately $1.5 \mathrm{~mm}$ to the right of the facial midline.

\section{TREATMENT OBJECTIVES AND PLAN}

\section{Treatment Objectives}

- The treatment objectives were as follows.

- Correction of skeletal class-III malocclusion.

- Correction of anterior and posterior cross bite.

- Correction of shifted midline.

\section{Treatment plan}

- Step-I: Restore the deciduous upper molar by conservative treatment.

- Step-II: Chin cap therapy.

- Step-III: Expansion of the upper arch anteriorly and bilaterally.

- Step-IV: Reassessment of the case for further treatment.

\section{Treatment Progress}

First, restore the grossly carious deciduous molar by Pulp therapy. A chin cap was fitted and was to be worn for 12 to $16 \mathrm{hr}$. per day to prevent forward growth of the mandible. Because of favorable growth, the anterior cross bite and class-III molar relationship were corrected with chin cap therapy. Then expansion of the upper arch was carried out bilaterally with upper removable expansion screw. The patient was followed up at 4 week interval during treatment. The patient cooperate at every step of treatment and treatment progress was good and there was no complication. (Fig 6)
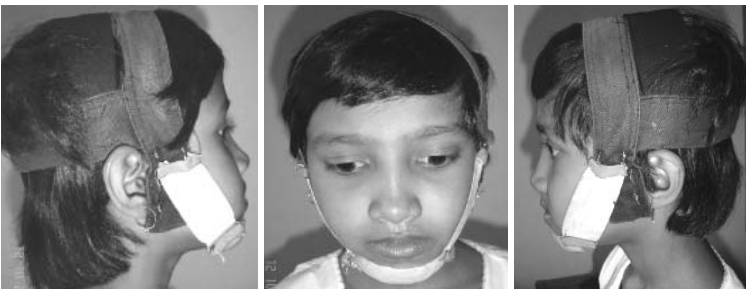

Fig. No. 06: Right, Frontal, Left oblique view

RESULT

The over all results of the orthodontic treatment was very good in the term of the following changes and improvements of the patient:

Dental Changes (Fig: 3,7,8, and 9)

Before treatment - anterior and posterior cross bite were present. Molar relation ship was class-III in Angles classification. Now anterior cross bite was corrected. Molar relationship was corrected and posterior cross bite correction is being continued on.
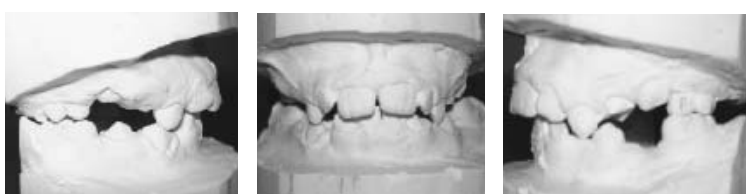

Fig. 7: Middle stage of treatment (right, frontal, left view)
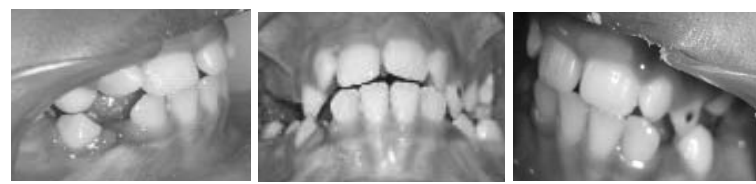

Fig. 8: Middle stage of treatment (intra oral view)
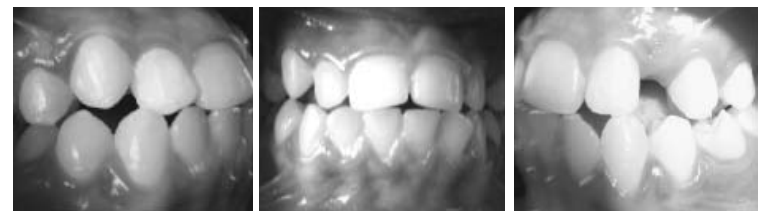

Fig. 9: After treatment (right, frontal, left view)

Profile Changes (Fig. 10) :

Before treatment - facial profile was concave and chin was protruded. Profile has been improved compared to before treatment. Her profile has been improved as chin protrusion has been disappeared.

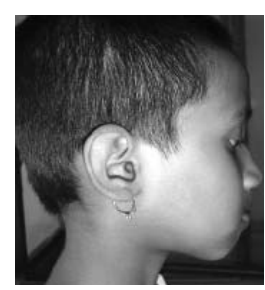

Fig. 10. Before treatment

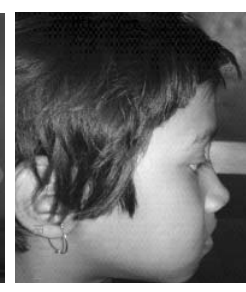

Middle stage of treatment.

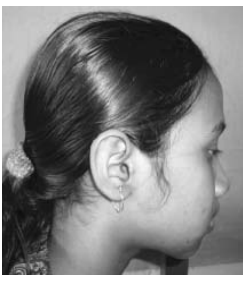

After treatment. 
Cephalometric changes (Fig. 11)

After treatment cephalometric changes has compared to the before treatment showed skeletal pattern has been changed.

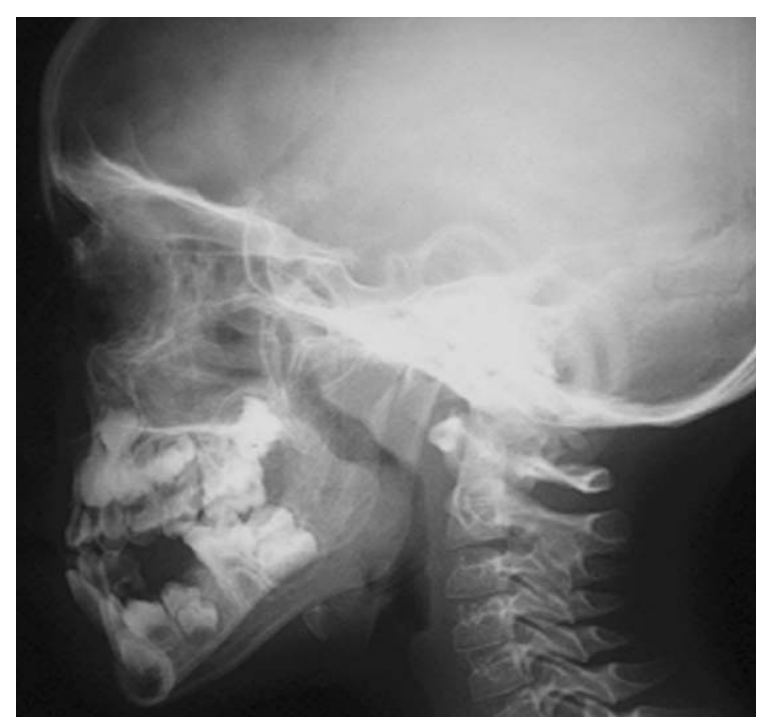

Fig. 11: Before treatment.

Patient and parent psychological changes

The parent and patients psychological satisfaction was achieved.

\section{DISCUSSION}

The use of chin cap for the prognathism has been known for about century. ${ }^{1}$ It is well known that the incidence of anterior cross bite and prognathism in mongoloid people is higher than that in the white population ${ }^{2}$. Chin cap therapy has been the usual technique for the treatment of growing patient with true skeletal class-III malocclusion.

Chin cap use is well known to affect the direction of growth of the mandible 3,4 . However, it is controversial whether chin cap used inhibit mandibular growth ${ }^{5,6}$. In chin cap therapy patient, TMJ parameter indicated - condylar forward bending, deeping and widening of the mandibular fossa, bone formation on the articular eminence, and narrowing of the clearance between the condyle and the fossa. Significant changes occurs in the superior and anterior condylar space and the anterior condylar space have been narrow because of the forward bending of the condyle. Orthopedic chin cap force is directed from the chin to the condyle posterosuperiorly. Mechanical stress is concentrated in the weakest part of the skeleton i,e the slender mandibular neck that is frequently broken in a maxillo facial traumatic injury.This site is speculated to be most responsive to mandibular orthopedic force. Therefore it is desirable that the chin cap therapy should be continued until the mandibular growth is complete.

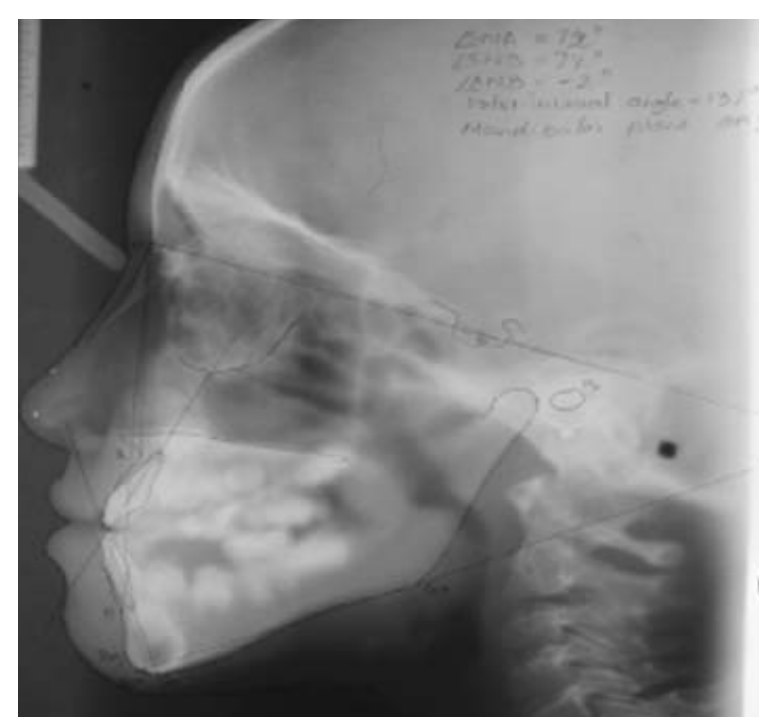

Middle stage of treatment

\section{REFERRENCE}

1. Angle EH. Treatment of malocclusion of teeth and fractures of the maxillae. New York: Dabor Science Publication, 1977: 268-71.

2. Susami R, Asai Y,Hirose K, et al . The prevalence of malocclusion in Japanese school children : part , the frequency of mandibular overjet. J Jpn Orthod Soc 1972;31:319-24

3. G.raber L.W. Chin cap therapy for mandibular prognathism ;Am J Orthod 1977;72;23-41.

4. Irie M , Nakamura S. Orthopaedic approach to severe skeletal classIII malocclusion. Am J Orthod 1975;67:377-92

5. Sugawara J, Asano T. Endo N, Mitani H.Long term effect of chin cap therapy on skeletal profile in mandibular prognathism. Am J Orthod Dentofac Orthop 1990;98:127-33.

6. Mitani $\mathrm{H}$, Fukasawa $\mathrm{H}$,Effect oh chincap force on the timing and amount of mandobular growth associated with anterior reversed occlusion. . Am J Orthod Dentofac Orthop 1986;90:4541-63.

\section{Correspondence :}

\section{Dr. Moklesur Rahman, BDS, FCPS}

Lecturer

Dept. of Orthodontics and Dentofacial Orthopedics

Dhaka dental College and Hospital

Mirpur- 14, Dhaka- 1206

Mobile : +8801711379555,

E-mail : mpino1971@yahoo.com 